\title{
O MAGMATISMO ARQUEANO DA REGIÃO DE TUCUMÃ-PROVÍNCIA MINERAL DE CARAJÁS: NOVOS RESULTADOS GEOCRONOLÓGICOS
}

\author{
VALTER GAMA DE AVELAR*, JEAN-MICHEL LAFON*, \\ FIRMINO COUTINHO CORREIA JR.* E EDÉSIO MARIA BUENANO MACAMBIRA **
}

\begin{abstract}
ARCHEAN MAGMATISM IN THE TUCUMÃ REGION-CARAJÁS MINERAL PROVINCE: NEW GEOCHRONOLOGICAL RESULTS New geochronological determinations have been performed by the $\mathrm{Pb} / \mathrm{Pb}$ method on zircons from Archean magmatic rocks of the Tucumã region in the Carajás Mineral Province (PMC). Zircons from a granodioritic orthogneiss of the Xingu Complex furnished an age of $2974 \pm 15 \mathrm{Ma}$. Zircons from a felsic metavolcanic rock at the top of the Tucumã greenstones and an associated metagranodiorite gave ages of $2868 \pm 8 \mathrm{Ma}$ and $2852 \pm 16 \mathrm{Ma}$, respectively. These results confirm that the principal episode of crustal growth in the southern part of the PMC took place between 3,0 and 2,85 Ga. The age of 2736 \pm 24 Ma obtained for zircons from a syn-collisional granitoid indicate the time of the main deformational event of the Itacaiúnas shear belt (northern part of the PMC). Comparison of the available geochronological results for the PMC point out a distinct time-related evolution between the different regions. The southern part of the PMC behaved as a stable crustal block during the evolution of the Itacaiúnas shear belt between $2,74 \mathrm{Ga}$ and $2,5 \mathrm{Ga}$. These new $\mathrm{Pb} / \mathrm{Pb}$ results are systematically older than the previous $\mathrm{Rb} / \mathrm{Sr}$ obtained on the same rocks, suggesting the open behaviour of the Rb/Sr chronometer in Archean rocks of the PMC.

Keywords: Magmatism, Archean, Zircon $\mathrm{Pb} / \mathrm{Pb}$ geochronology, Carajás Mineral Province

RESUMO Novos dados geocronológicos foram obtidos pelo método $\mathrm{Pb} / \mathrm{Pb}$ em monocristais de zircão de rochas magmáticas arqueanas da região de Tucumã, na Província Mineral de Carajás (PMC). Zircões de um ortognaisse granodiorítico do Complexo Xingu forneceram uma idade de $2974 \pm 15 \mathrm{Ma}$, enquanto que zircões provenientes de uma rocha metavulcânica félsica do topo das sequências de greenstones belts do Grupo Tucumã e de um metagranodiorito associado a essas sequências definiram idades de $2868 \pm 8$ Ma e $2852 \pm 16$ Ma, respectivamente. Esses dados confirmam que o período entre 3,0-2,85 Ga constitui o principal episódio de formação da crosta siálica na porção sul da PMC. A idade de $2736 \pm 24 \mathrm{Ma}$, obtida para zircões de um granito estratóide sin-colisional, indica a época de estruturação do Cinturão de Cisalhamento Itacaiúnas (porção norte da PMC) e desvincula esse magmatismo daquele gerador dos granitóides dos terrenos granito-greenstones. A comparação dos dados geocronológicos para as porções norte e sul da PMC, demonstra que essas regiões tiveram uma evolução diferente - a região sul comportou-se como um bloco crustal estável, durante a evolução do Cinturão de Cisalhamento Itacaiúnas, a norte. Finalmente, as idades $\mathrm{Pb} / \mathrm{Pb}$ em zircão, obtidas para as rochas da região de Tucumã são sistematicamente superiores às idades $\mathrm{Rb} / \mathrm{Sr}$, confirmando o comportamento em sistema aberto do cronometro $\mathrm{Rb} / \mathrm{Sr}$ das rochas arqueanas da $\mathrm{PMC}$.

Palavrus-chaves: Magmatismo, Arqueano, Geocronologia $\mathrm{Pb} / \mathrm{Pb}$ em zircão, Província Mineral de Carajás
\end{abstract}

INTRODUÇÃo A Província Mineral de Carajás (PMC), situada na porção oriental do Cráton Amazônico, é uma das regiões melhor estudadas da Amazónia devido seus importantes recursos minerais. Entretanto, se algumas áreas dessa província, como as regiões da Serra dos Carajás ou de Rio Maria, foram alvo de estudos sistematizados do ponto de vista geológico, metalogenético e geocronológico, outras ainda não o foram (regiões de Tucumã, Xinguara e Redenção), o que tem dificultado a elaboração de um quadro evolutivo integrado.

A região de Tucumã, na porção Sudoeste da PMC (Fig. 1), foi incorporada no contexto dessa província, graças aos trabalhos de mapeamento geológico realizados recentemente pela CPRM, que permitiram o esboço do quadro litoestratigráfico da área. Os dados geocronológicos disponíveis para essa região são muito limitados e foram obtidos em grande parte pelo método $\mathrm{Rb} / \mathrm{Sr}$, sendo estes insuficientes para sustentar um modelo evolutivo.

$\mathrm{O}$ método de datação por evaporação direta de $\mathrm{Pb}$ em zircão constitui uma ferramenta apropriada para a determinação da idade de cristalização de rochas antigas. O uso desta técnica é particularmente válida em regiões onde o acervo de informações geocronológicas ainda é bastante reduzido ou constituído essencialmente por dados obtidos através de geocronômetros sensíveis à perturbações pós-cristalização (Gaudette et al. 1993, 1998, Macambira et al. 1994).

Nesse trabalho, o método de evaporação direta de $\mathrm{Pb}$ em zircão foi aplicado em algumas das unidades magmáticas mais representativas da região de Tucumã. Objetivou-se assim, trazer referências cronológicas novas para as unidades magmáticas arqueanas e investigar suas relações com a estruturação geotectônica regional. Esses dados visam também estabelecer as correlações com a cronologia dos eventos termo-tectônicos evidenciados em outras regiões da PMC.

A PROVÍNCIA MINERAL DE CARAJÁS: PRINCIPAIS CARACTERÍSTICAS LITOESTRATIGRÁFICAS O quadro geológico da PMC foi delineado por Hirata et al. (1 982) e DOCEGEO (1988), os quais elaboraram os primeiros trabalhos de síntese sobre a mesma. Os trabalhos de mapeamento geológico desenvolvidos pela CPRM a partir do final da década de 80, através do Programa Grande Carajás, muito contribuíram para aprimorar o conhecimento deste quadro. Esses estudos levaram Araújo et al. (1994) e Costa et al. (1994, 1995) à proposição de integração geológica das diferentes folhas que abrangem a Província Mineral de Carajás (Folhas SB.22-X.C/Serra

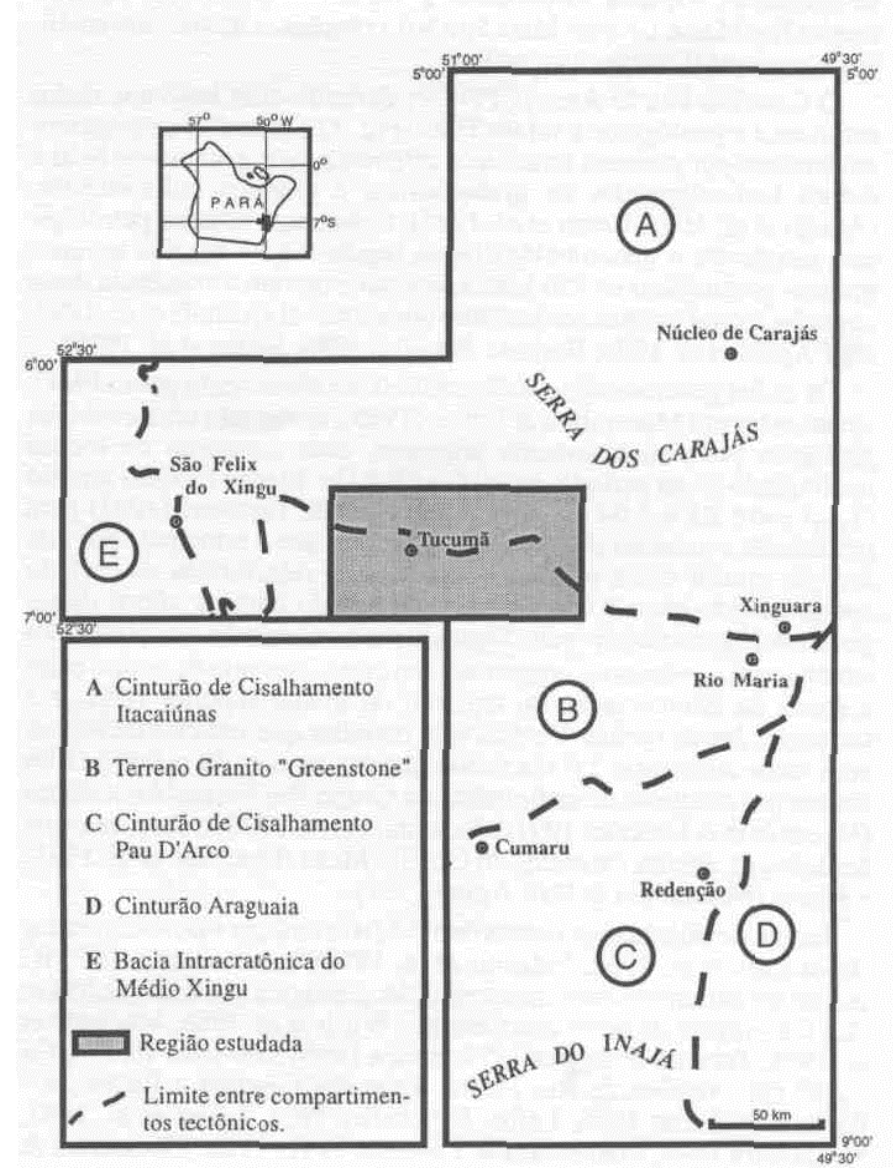

Figural - Arcabouço estrutural da Província Mineral de Carajás, segundo Araújo et al. (1994). 
Pelada; SB.22-Z.A/Serra dos Carajás; SB.22-Z.C/Xinguara; SB.22X.A/Redenção e SB.22-Y.B/São Félix do Xingu; Fig. 1).

$\mathrm{O}$ arranjo estrutural entre as principais unidades litológicas da porção sul da Província Mineral de Carajás está relacionado à atuação de um evento de colisão oblíqua de segmentos continentais, ocorrido no final do Arqueano e com duração de pelo menos $250 \mathrm{Ma}$. Esse evento expressa-se através de 3 compartimentos geotectônicos orientados na direção E-W, formados pêlos terrenos granito-greenstones preservados (terrenos de médio a baixo grau), que são cercados a norte e a sul por cinturões de cisalhamentos (Itacaiúnas e Pau D'Arco, res-pectivamente) que constituem terrenos de alto grau metamórfico (Ara-újo et al. 1994, Costa et al. 1995) e Costa \& Hasui 1997), (Fig. 1).

Para a região norte da PMC (Bacia dos Carajás), Teixeira \& Eggler (1994), propuzeram um modelo geotectônico baseado em dados estruturais, petrográficos, geoquímicos e isotópicos, sugerindo um processo de placas em convergência oblíqua. Este modelo envolve um contexto de subducção seguida pela colisão de dois terrenos continentais no arqueano, onde a margem ativa (ao norte), representada pelo Complexo Xingu, constitui o embasamento da Bacia dos Carajás, enquanto a margem passiva (ao sul) corresponde ao terreno granito-greenstone (Supergrupo Andorinhas). Segundo os autores este processo perdurou por aproximadamente $200 \mathrm{Ma}$.

O Cinturão de Cisalhamento Itacaiúnas $(\mathrm{CCI})$, a norte, é constituído por faixas e lentes de rochas granulíticas (Complexo Pium), gnaisses localmente migmatizados (Complexo Xingu), rochas supracrustais (Grupo Sapucaia) e granitóides estratóides (Suite Plaque), dispostas segundo direções E-W. O Terreno Granito-Greenstone do Sul do Pará (TGG) é formado por faixas orientadas nas direções E-W, NW-SE e NE-SW, sendo composto principalmente por rochas metavulcanosedimentares (Grupos Andorinhas e Tucumã), granitóides (Granodiorito Rio Maria, Granito Mata Surrão), complexos máfico-ultramáficos e gnaisses (Gnaisse Mogno).

O Cinturão Pau D'Arco (CPD) foi definido com base nos dados estruturais e geológicos a sul do TGG (Fig. 1) e constituí-se predominantemente por gnaisses tonalíticos migmatizados, greenstone belts $\mathrm{e}$ corpos lenticularizados de granodioritos e granitos milonitizados, (Araújo et al. 1994, Costa et al. 1995). Entretanto, estudos petrológicos, estruturais e geocronológicos na região logo a sul dos terrenos granito- greenstones de Rio Maria não confirmaram a existência deste cinturão, a qual permanece bastante questionável (Althoff et al. 1995, Dali'Agnol et al 1996, Barbosa \& Lafon 1996, Souza et al 1996).

Os dados geocronológicos disponíveis até o momento para a PMC, sintetizados em Macambira \& Lafon (1995), sustentam uma evolução geológica predominantemente arqueana, com formação de rochas restringindo-se ao período de 3,0 Ga a 2,5 Ga. Idades-modelo Sm-Nd $\left(\mathrm{T}_{\mathrm{DM}}\right)$ entre 2,8 e 3,04 Ga obtidas por Sato \& Tassinari (1997) para granitóides e gnaisses da PMC, confirmaram que a principal época de acreção crustal dessa província está mesmo relacionada ao período compreendido entre 3,0 e 2,85 Ga, de acordo com os vários dados geocronológicos disponíveis. Segundo o mesmo estudo, as correlações isotópicas $\left(\varepsilon_{\mathrm{Nd}}\right.$ versus $\left.\varepsilon_{\mathrm{Sr}}\right)$ sugeriram um curto intervalo de tempo entre a época da diferenciação do material do manto superior (DM) e a formacão dessas rochas. Porém, vale ressaltar que indícios de rochas com idade superior à $3,0 \mathrm{Ga}$ foram obtidos através do método U-Pb em zircões detríticos de sedimentos do Grupo Rio Fresco/Andorinhas (Macambira \& Lancelot 1991, Macambira et al. 1998) e como núcleos herdados de zircões extraídos do Granito Musa (Machado et al 1991) e Jamon (Macambira \& Dall'Agnol 1997).

Embora evidências de rochas de até 3,0 Ga tenham sido encontradas (Rodrigues et al. 1992, Pidgeon et al 1998), o setor norte da PMC parece ter experimentado uma evolução geológica posterior $(2,85 \mathrm{Ga}$ -2,5 Ga - região da Serra dos Carajás - Wirth et al 1986, Machado et ai. 1991, Teixeira \& Eggler 1994, Souza 1996) à do setor sul (3,0 Ga

- 2,87 Ga - regiões de Rio Maria, Serra dos Gradaús e Redenção Barbosa \& Lafon 1996, Lafon \& Scheller 1994, Lafon et al 1994, Macambira 1992, Macambira \& Lancelot 1991, 1996, Macambira \& Scheller 1994, Pimentel \& Machado 1994).

$\mathrm{Na}$ região da Serra dos Carajás foram destacados três eventos tectono-metamórficos com idades de 2,85 Ga, 2,77-2,73 Ga e 2,58$2,53 \mathrm{Ga}$ (Machado et al 1991). Esses eventos não foram ainda identificados com clareza nas outras porções da província. No entanto, os dados $\mathrm{Rb} / \mathrm{Sr}$ em rocha total e $\mathrm{K} / \mathrm{Ar}$ em minerais, obtidos em rochas arqueanas dessas porções, indicam idades entre $2,75 \mathrm{Ga}$ e 2,50 Ga (Gastai et al 1987, Montai vão et al. 1988, Lafon \& Macambira 1990, Lafon et al 1991, Duarte et al 1991, Macambira et al 1988, 1991), induzindo à possibilidade de que esses eventos tenham atingido toda aPMC.

Durante o Paleoproterozóico, a PMC foi submetida regionalmente a uma movimentação extensional, geradora de falhas normais NW-SE e de transferência NE-SW (Costa et al 1991, Costa \& Hasui 1992). Esse evento termo-tectônico propiciou a formação de rochas vulcânicas e sedimentares (Grupo Uatumã e Formação Triunfo, respectivamente), bem como a intrusão de granitos anorogênicos (amplamente espalhados na província), e corpos básico-ultrabásicos (Costa et al 1991, Costa \& Hasui 1992, Costa et al 1995 e Dall' Agnol et al 1994).

\section{CONTEXTO GEOLÓGICO DA REGIÃO DE TUCUMÃ A}

região de Tucumã ocupa as porções sudeste e sudoeste, respectivamente, das Folhas SB.22-Y.B e SB.22-Z.A (Fig. 2), e abrange os domínios do Terreno Granito-Greenstone do Sul do Pará e do Cinturão de Cisalhamento Itacaiúnas, ambos de idades arqueanas (Costa et al 1993, Macambira \& Vale 1997). A região é marcada ainda, por unidades Proterozóicas englobadas nas Suítes Intrusivas Cateté e Velho Guilherme. A unidade Cateté é formada por rochas máfico-ultramáficas (serpentinitos, piroxenitos e gabronoritos), não metamorfisadas e intrusivas nas rochas do CCI (Complexo Xingu e Granito Plaque). A Suíte Velho Guilherme é constituída por granitos de forma arredondada (Granitos Seringa e Velho Guilherme), apresentando uma composição monzogranítica a álcali-feldspato granítica e intrusivos nas rochas dos TGG (Granodiorito Rio Maria e Grupo Tucumã).

O Terreno Granito-Greenstone do Sul do Pará Este compreende várias faixas de rochas supracrustais incluídas no Grupo Tucumã (GT), orientadas preferencialmente na direcão NW-SE, e uma expressiva fração do Granodiorito Rio Maria (GRM). A estruturação desse terreno é definida por um arranjo anastomosado de zonas de Cisalhamento oblíquas e transcorrentes, que afetam principalmente as rochas do GT. As relações entre os granitóides do GRM e as rochas supracrustais do GT são definidas por zonas de Cisalhamento relacionadas a um sistema de transcorrência dextral e desenvolvidas em regime de transpressão (Costa et al 1993, Macambira \& Vale 1997). O Grupo Tucumã foi denominado formalmente por Araújo \& Maia (1991) para descrever as rochas supracrustais do extremo S W da Folha Serra dos Carajás (SB.22-Z.A), anteriormente englobadas no Supergrupo Andorinhas (DOCEGEO 1988). Este é formado por sequências metavulcano-sedimentares, que compreende uma intercalação de rochas metavulcânicas máficas, félsicas e metassedimentos (Macambira \& Vale 1996). O Granodiorito Rio Maria é constituído por rochas granodicríticas, com tonalitos e monzogranitos subordinados, distribuídas principalmente na porção sudoeste da região de Tucumã. Essas rochas relacionam-se com os ortognaisses do Complexo Xingu através de uma zona gradacional, onde coexistem porções preservadas do TGG e retrabalhadas do CCI (Araújo \& Maia 1991, Costa et al 1993). Macambira \& Vale (1997) reconheceram dois corpos petrograficamente distintos. Um desses corpos ocorre na bacia do Igarapé Manelão e possui natureza monzogranítica. Apresenta-se milonitizado e raramente exibe texturas ígneas preservadas. O outro corpo, de composição granodiorítica, ocorre nas adjacências da cidade de Ourilândia do Norte. Este apresenta feições deformacionais semelhantes àquelas encontradas no corpo anterior, porém com maior frequência de texturas ígneas preservadas.

O Cinturão de Cisalhamento Itacaiúnas Ocupando a porção norte da região de Tucumã (Fig. 2), o CCI é constituído por ortognaisses granodioríticos e tonalíticos do Complexo Xingu (CX), rochas supracrustais do Grupo Sapucaia (GS) e granitóides estratóides do Granito Plaque (GP). O arcabouço estrutural é marcado por cavalgamentos dúcteis, orientados preferencialmente na direção $\mathrm{E}-\mathrm{W}$, que se projetam nas regiões de contato entre as principais unidades, definindo um sistema imbricado fortemente inclinado para norte. Esse sistema é decorrente de cinemática sinistrai, com lineação de estiramento orientada segundo NE/SW, e mergulho de $20^{\circ}$ para NE indicando um deslocamento de massa de SW para NE (Costa et al 1993, 1994).

Os ortognaisses do CX constituem a unidade de maior distribuição na área estudada, onde dominam gnaisses tonalíticos, trondhjemíticos e granodioríticos, com termos graníticos subordinados. Essas rochas mantém contatos gradacionais com os litotipos do GRM, enquanto que, com as rochas do GS e do GP estes são marcados por zonas de cavalgamentos dúcteis (Macambira \& Vale 1997). O GS é constituído por um conjunto de rochas supracrustais, caracterizadas como um greenstone belt, similar aos Grupos Tucumã e Andorinhas, retrabalhado em regime de Cisalhamento dúctil (Araújo \& Maia 1991). Na área 
de Tucumã, o GS estende-se em faixas alongadas e adelgaçadas, com orientação principal E-W, mantendo contato através de zonas de cisalhamento com as rochas do CX e do GP. O Granito Plaque agrupa corpos de moscovita-biotita leucogranitos, alongados na direção E-W, que se espalham por toda a faixa de domínio do CCI. Esses corpos, interpretados como produtos de fusão dos ortognaisses do CX (Macambira et al. 1996), exibem uma deformação progressiva, variando desde proto- a ultramilonitos, e mantém relações de contatos com as demais unidades arqueanas do CCI através de zonas de cisalhamento dúctil (Araújo et al. 1988, João \& Araújo 1992).

Os dados geocronológicos para a região de Tucumã são bastante reduzidos. Não existem referências geocronológicas para as rochas do GT. Para os monzogranitos e granodioritos do GRM, dispunha-se de idades $\mathrm{Rb} / \mathrm{Sr}$ em rocha total de $2739 \pm 23 \mathrm{Ma}$ (Ia) e $2677 \pm 50 \mathrm{Ma}$ (Ia), (Lafon et al. 1991). Estas poderiam representar tanto a idade de cristalização dos corpos, como de reabertura do sistema isotópico $\mathrm{Rb} / \mathrm{Sr}$, provocada por posterior evento deformacional que afetou essas rochas. Quanto às unidades do $\mathrm{CCI}$, reconhecia-se apenas uma idade $\mathrm{Rb} / \mathrm{Sr}$ em rocha total de $2574 \pm 57 \mathrm{Ma}$ (l a) para gnaisses granodioríticos do CX, localizados no extremo oeste da Folha SB.22-Y.B, a oeste da região de Tucumã (Lafon et al. 1991). Finalmente, para as unidades Proterozóicas os dados geocronológicos disponíveis para um corpo da Suíte Intrusiva Cateté (Serra da Onça) registram uma idade Sm-Nd de $2,4 \mathrm{Ga}$, com valores positivos de $\varepsilon_{\mathrm{Nd}}$ que são compatíveis com uma origem a partir do manto empobrecido (Macambira \& Tassinari 1998). Os granitos Velho Guilherme e Seringa forneceram idades respectivas de $1874 \pm 30 \mathrm{Ma}(\mathrm{Pb}-\mathrm{Pb}$ em rocha total, Lafon et al. 1995) e $1893 \pm$ $15 \mathrm{Ma}$ (Pb-Pb em zircão, Avelar et al. 1994).

DESCRIÇÃO DAS ROCHAS ESTUDADAS Para a caracterização geocronológica do magmatismo arqueano da região de Tucumã, foram investigadas rochas magmáticas de quatro unidades estratigráficas. No âmbito do CCI, um ortognaisse granodiorítico do Complexo Xingu e um granitóide do Granito Plaque foram escolhidos, enquanto que no âmbito do TGG, um metagranodiorito representante do Granodiorito Rio Maria e uma rocha metavulcânica félsica pertencente ao Grupo Tucumã foram selecionados (Fig. 2).
Ortognaisse Granodiorítico do Complexo Xingu A rocha, coletada a cerca de $10 \mathrm{~km}$ ao norte de Ourilândia do Norte, consiste de um ortognaisse granodiorítico cinza-claro, intensamente deformado, com bandamento gnáissico bem definido e por vezes migmatizado. Comumente, essas rochas são entrecortadas por veios de composição granítica, de espessura variável de alguns milímetros até $10 \mathrm{~cm}$, com orientação preferencial SW-NE. Esses veios possuem granulação média a grossa e textura granular, com pórfiros de feldspato potássico.

A mineralogia principal compreende plagioclásio, feldspato potássico, quartzo, biotita e anfibólio. Os acessórios são a moscovita, titanita, zircão, fluorita e opacos. Sericita, clorita, epidoto e argilo-minerais ocorrem como minerais secundários. A textura é granonematoblástica, com pórfiros de plagioclásio e feldspato potássico envolvidos por uma matriz fina-média constituída por plagioclásio, quartzo e biotita.

A deformação é marcada por feiç̃es de recristalização intensa e formação de subgrãos de quartzo, estirados e fraturados internamente. Os cristais porfiríticos de plagioclásio exibem desde estiramento (elípticos), até uma orientação incipiente. Entre os porfiroclastos, agregamse subgrãos de quartzo e lamelas de biotita. Estes aspectos texturais sugerem que a rocha sofreu um processo de protomilonitização.

As características petroquímicas dos ortognaisses do CX indicam um caráter cálcio-alcalino, sugerindo uma geração em ambientes compressivos sin- à pós-colisionais (Macambira \& Vale 1997).

\section{Rocha Metavulcânica Félsica do Grupo Tucumã A}

amostra foi coletada a aproximadamente $2 \mathrm{~km}$ a sudeste da cidade de Tucumã. Trata-se de uma rocha vulcânica félsica milonitizada, formada essencialmente por plagioclásio, quartzo policristalino e biotita. Sericita e clorita aparecem como minerais secundários, enquanto zircão e opacos como acessórios.

A rocha foi afetada por uma deformação heterogénea em escala regional. Apresenta uma alternância de bandas com diferente grau de deformação. Algumas apresentam feições reliquiares com fenocristais de plagioclásio pouco alterados, imersos numa matriz essencialmente quartzo-feldspática recristalizada e sericitizada. Outras, mais deformadas, apresentam foliação milonítica bem definida por minerais micáceos. Essas bandas são marcadas por feições tipo kink-bands no
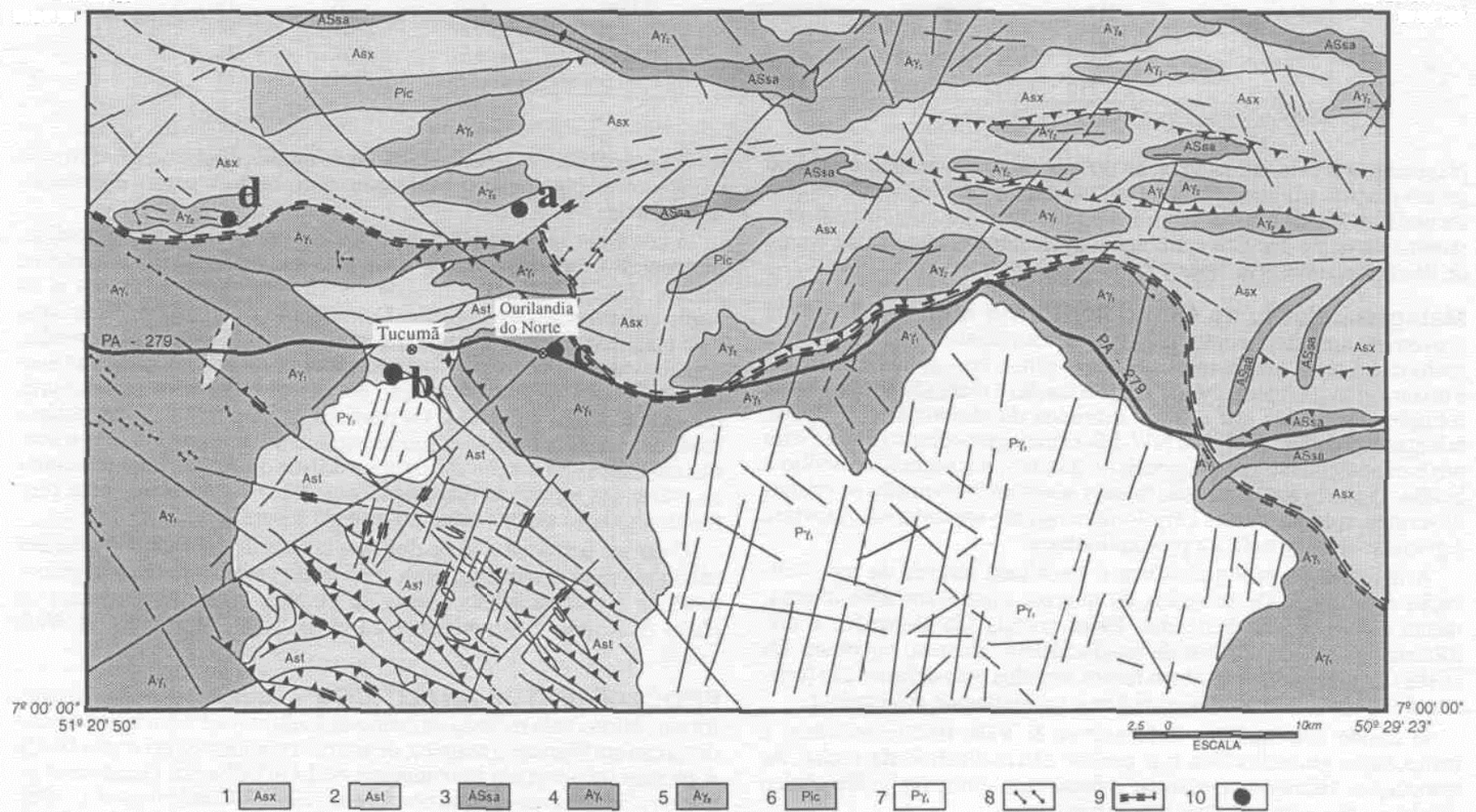

Figura 2 - Mapa geológico da região de Tucumã (simplificado a partir das Folhas SB.22-Y.B-São Félix do Xingu e SB.22-Z.A-Serra dos Carajás, CPRM) e localização das amostras analisadas. 1. Ortognaisses do CX; 2. Sequências de greenstone belts (GT); 3. Sequências de greenstone belts (GS); 4. Metagranitóides (GRM); 5. Granitóides estratóides (GP); 6. Suite Intrusiva Cateté; 7. Granitos proterozóicos; 8. Diques; 9. Limites dos compartimentos geotectônicos; 10. Pontos de amostragem: (a) Ortognaisse granodiorítico do CX. (b) Rocha metavulcânica félsica do GT. (c) Metagranodiorito do GRM. (d) Granitóide estratóide do GP. 
Tabela l-Dados isotópicos Pb-Pb em zircão das rochas arqueanas da região de Tucumã.

\begin{tabular}{|c|c|c|c|c|c|c|c|}
\hline Zircăo & $\begin{array}{l}\text { Número de } \\
\text { razōes }\end{array}$ & ${ }^{204} \mathbf{P b} /^{306} \mathbf{P b}$ & $1 \sigma$ & $\left({ }^{257} \mathbf{P b} /{ }^{256} \mathrm{~Pb}\right) \mathrm{c}$ & $1 \sigma$ & Idade (Ma) & $\begin{array}{c}2 \sigma \\
(\mathbf{M a})\end{array}$ \\
\hline \multicolumn{8}{|c|}{ Ortognaisse Granodioritico (Complexo Xingu) } \\
\hline $\begin{array}{l}\text { CXV/01 } \\
\text { CXV/02 } \\
\text { CXV/03 } \\
\text { CXV/04 } \\
\text { CXV/05 } \\
\text { CXV/08 } \\
\text { CXV/09 } \\
\text { CXV/11 } \\
\text { CXF/12 } \\
\text { CXFV/16 }\end{array}$ & $\begin{array}{c}96 \\
48 \\
114 \\
78 \\
48 \\
66 \\
72 \\
90 \\
54 \\
54 \\
\Sigma=720\end{array}$ & $\begin{array}{l}0.000197 \\
0.000097 \\
0.000151 \\
0.000111 \\
0.000059 \\
0.000111 \\
0.000041 \\
0.000128 \\
0.000122 \\
0.000248\end{array}$ & $\begin{array}{l}0.000029 \\
0.000020 \\
0.000022 \\
0.000020 \\
0.000012 \\
0.000029 \\
0.000009 \\
0.000065 \\
0.000020 \\
0.000020\end{array}$ & $\begin{array}{c}0.2154 \\
0.2174 \\
0.2118 \\
0.2207 \\
0.2213 \\
0.2150 \\
0.2104 \\
0.2186 \\
0.2163 \\
0.2160 \\
\text { Média }\end{array}$ & $\begin{array}{c}0.0022 \\
0.0025 \\
0.0016 \\
0.0015 \\
0.0006 \\
0.0023 \\
0.0031 \\
0.0014 \\
0.0012 \\
0.0020 \\
\text { nderada: }\end{array}$ & $\begin{array}{l}2947 \\
2961 \\
2920 \\
2986 \\
2991 \\
2944 \\
2909 \\
2970 \\
2953 \\
2951 \\
2974\end{array}$ & $\begin{array}{c}32 \\
36 \\
24 \\
22 \\
8 \\
34 \\
48 \\
22 \\
16 \\
30 \\
15\end{array}$ \\
\hline \multicolumn{8}{|c|}{ Rocha metavulcânica félsica (Grupo Tucuma) } \\
\hline $\begin{array}{l}\text { ATSF/07 } \\
\text { ATSF/08 } \\
\text { ATSF/09 } \\
\text { ATSF/10 } \\
\text { ATSF/11 } \\
\text { ATSF/12 } \\
\text { ATSF/17 } \\
\text { ATSF/18 }\end{array}$ & $\begin{array}{c}96 \\
90 \\
108 \\
120 \\
96 \\
78 \\
48 \\
30\end{array}$ & $\begin{array}{l}0.000109 \\
0.000183 \\
0.000145 \\
0.000186 \\
0.000067 \\
0.000093 \\
0.000245 \\
0.000150\end{array}$ & $\begin{array}{l}0.000021 \\
0.000022 \\
0.000023 \\
0.000018 \\
0.000014 \\
0.000017 \\
0.000069 \\
0.000105\end{array}$ & $\begin{array}{l}0.2045 \\
0.2047 \\
0.2049 \\
0.2083 \\
0.1979 \\
0.2047 \\
0.2088 \\
0.2070\end{array}$ & $\begin{array}{l}0.0011 \\
0.0007 \\
0.0009 \\
0.0010 \\
0.0029 \\
0.0005 \\
0.0024 \\
0.0020\end{array}$ & $\begin{array}{l}2863 \\
2865 \\
2866 \\
2893 \\
2809 \\
2865 \\
2896 \\
2882\end{array}$ & $\begin{array}{c}18 \\
10 \\
14 \\
16 \\
48 \\
8 \\
38 \\
30\end{array}$ \\
\hline \multicolumn{3}{|c|}{$\Sigma=666$} & & \multicolumn{2}{|c|}{ Média ponderada: } & 2868 & 8 \\
\hline \multicolumn{8}{|c|}{ Metagranodiorito (Granodiorito Rio Maria) } \\
\hline $\begin{array}{l}\text { TTGV/02 } \\
\text { TTGV/03 } \\
\text { TTGF/09 } \\
\text { TTGF/10 } \\
\text { TTGF/12 } \\
\text { TTGF/13 }\end{array}$ & $\begin{array}{c}108 \\
54 \\
42 \\
60 \\
30 \\
48 \\
\Sigma=342\end{array}$ & $\begin{array}{l}0.000122 \\
0.000201 \\
0.000110 \\
0.000193 \\
0.000177 \\
0.000059\end{array}$ & $\begin{array}{l}0.000021 \\
0.000070 \\
0.000150 \\
0.000046 \\
0.000114 \\
0.000054\end{array}$ & $\begin{array}{c}0.2029 \\
0.2089 \\
0.2041 \\
0.1970 \\
0.2008 \\
0.1994 \\
\text { Média }\end{array}$ & $\begin{array}{c}0.0007 \\
0.0017 \\
0.0009 \\
0.0052 \\
0.0042 \\
0.0011 \\
\text { nderada: }\end{array}$ & $\begin{array}{l}2850 \\
2897 \\
2860 \\
2801 \\
2833 \\
2822 \\
2852\end{array}$ & $\begin{array}{l}10 \\
26 \\
14 \\
86 \\
68 \\
18 \\
16\end{array}$ \\
\hline \multicolumn{8}{|c|}{ Granitóide estratóide (Granito Plaquê) } \\
\hline $\begin{array}{l}\text { GPV/10 } \\
\text { GPV/11 } \\
\text { GPFV/18 } \\
\text { GPFV/19 }\end{array}$ & $\begin{array}{c}36 \\
114 \\
30 \\
30 \\
\Sigma=210\end{array}$ & $\begin{array}{l}0.000142 \\
0.000199 \\
0.000198 \\
0.000119\end{array}$ & $\begin{array}{l}0.000139 \\
0.000027 \\
0.000112 \\
0.000051\end{array}$ & $\begin{array}{c}0.1958 \\
0.1881 \\
0.1949 \\
0.1894 \\
\quad \text { Média }\end{array}$ & $\begin{array}{c}0.0034 \\
0.0007 \\
0.0020 \\
0.0020 \\
\text { nderada: }\end{array}$ & $\begin{array}{l}2792 \\
2726 \\
2784 \\
2737 \\
\mathbf{2 7 3 6}\end{array}$ & $\begin{array}{l}56 \\
12 \\
34 \\
36 \\
24\end{array}$ \\
\hline
\end{tabular}

$\mathrm{C}$ : corrigido do $\mathrm{Pb}$ comum

plagioclásio e pela recristalização do quartzo, cujo arranjo cristalino geram junções tríplices, texturas em mosaico e venulações de origem secundária. Os dados petroquímicos indicam uma composição predominantemente dacítica e ambiente geotectônico semelhante à arco de ilhas (Macambira \& Vale 1997).

Metagranodiorito do Granodiorito Rio Maria A amostra provém de um afloramento da cidade de Ourilândia do Norte. É uma rocha cinza-clara, estruturalmente heterogénea, com granulação média e textura granonematoblástica. A deformação é marcada por planos de foliação ressaltados por cristais estirados de plagioclásio e biotita, orientados segundo a direção NW-SE. O metagranodiorito é composto predominantemente por plagioclásio, quartzo, microclina, anfibólio e biotita. $\mathrm{O}$ zircão e a apatita são termos acessórios, enquanto os cristais de sericita, epidoto, clorita e argilo-minerais são secundários. A textura é granular alotriomórfica a protomilonítica.

A deformação protomilonítica é ressaltada através da recristalização e formação de subgrãos de quartzo microfraturados internamente e com bordas denteadas. Esses cristais são alongados e distribuem-se entre os pórfiros de plagioclásio e feldspato potássico. Os cristais de plagioclásio também foram afetados pela deformação (cristais alongados, com bordas corroídas e parcialmente orientados).

O estudo petroquímico (Macambira \& Vale 1997) confirmou a composição granodiorítica e o caráter cálcio-alcalino da rocha. As associaçốes tectono-magmáticas indicam um ambiente geotectônico similar ao dos arcos de ilhas modernos.

Granitóide Estratóide do Granito Plaquê O corpo estudado localiza-se a aproximadamente $15 \mathrm{~km}$ a noroeste da cidade de Tucumã e apresenta-se alongado na direção E-W. Aflora sob a forma de grandes blocos de composição essencialmente granítica, exibindo uma coloração rosa-clara e deformação moderada. A foliação é incipiente, sendo ressaltada pela orientação das lamelas de biotita, dispostas entre cristais alongados de plagioclásio e feldspato potássico. A textura é granonematoblástica.

A composição mineralógica principal é constituída por microclina, plagioclásio, quartzo, biotita e moscovita, tendo como acessórios, zircão, titanita, apatita e opacos. A sericita, epidoto, clorita e os argilo-minerais são secundários. Comumente, os cristais de microclina e de plagioclásio ocorrem como pórfiros imersos numa matriz média, constituída de quartzo, plagioclásio e biotita. O quartzo apresenta uma recristalização intensa e formação de subgrãos estirados com fraturas internas e bordas corroídas. Os pórfiros de microclina e plagioclásio mostram também feições como alongamento, fraturas internas e bordas corroídas. As macias de alguns pórfiros de plagioclásio mostramse retorcidas (kink). A disposição dos cristais caracteriza uma protomilonitização e dá à rocha um aspecto bandado.

$\mathrm{O}$ estudo petroquímico de diversos corpos do GP indica um caráter cálcio-alcalino à alcalino, com uma composição granítica a granodiorítica e características típicas de granitos crustais sin-colisionais (João \& Araújo 1992, Macambira et al. 1996, Macambira \& Vale 1997).

PROCEDIMENTOS ANALÍTICOS Os dados geocronológicos foram obtidos pelo método de evaporação direta de $\mathrm{Pb}$ em monocristais de zircão em filamento simples, de acordo com Olszewski et al. (1990). A técnica foi adaptada às condições do LGI/UFPa por Gaudette et al. (1993) e descrita em detalhe por Avelar (1996) e Gaudette et al (1998). Esse método é uma adaptação daquele desenvolvido por Kober (1986, 1987) para a análise isotópica de $\mathrm{Pb}$ de zircão em filamento duplo.

Os zircões foram extraídos de cerca de $20 \mathrm{~kg}$ de amostra de rocha fresca e de $30 \mathrm{~kg}$ do saprólito correspondente. Não foram encontradas diferenças entre os resultados isotópicos de zircões oriundos da amostra não intemperizada e do saprólito. Portanto, os dados isotópi- 
cos dos zircões de ambos materiais foram tratados em conjunto para obtenção da idade da rocha.

Após trituração, bateamento e peneiramento das amostras, os zircões provenientes da fração granulométrica entre $0,088 \mathrm{~mm}$ e $0,125 \mathrm{~mm}$ foram separados com auxilio de elutriação, separador magnético Isodynamic Frantz e líquidos pesados. Os cristais de zircão escolhidos foram depositados num filamento de rênio em forma de "canoa". As análises isotópicas foram realizadas com um espectrômetro de massa VG Isomass54E, equipado com um detetor DALY, para a determinação das razões ${ }^{207} \mathrm{~Pb} /{ }^{206} \mathrm{~Pb}$ em incrementos sucessivos de temperatura.

Para cada zircão, uma idade é calculada a partir do conjunto de pelo menos 5 blocos de razões ${ }^{207} \mathrm{~Pb} /{ }^{206} \mathrm{~Pb}$ que define um "platô" com idade constante e com razão ${ }^{206} \mathrm{~Pb} /{ }^{204} \mathrm{~Pb}>2500$. Cada bloco representa a determinação sequencial de 6 razões ${ }^{207} \mathrm{~Pb} /{ }^{206} \mathrm{~Pb}$. A idade da rocha é determinada a partir da média ponderada das idades dos cristais analisados. Os resultados são apresentados com $2 \sigma$ de desvio padrão.

RESULTADOS GEOCRONOLÓGICOS Os resultados analíti$\cos \mathrm{Pb} / \mathrm{Pb}$ para os zircões das diversas amostras estudadas neste trabalho estão sumariados na Tabela 1 .

Os zircões do ortognaisse granodiontico do CX mostram uma coloração que varia de rosado a castanho-claro, sendo geralmente translúcidos a transparentes, com brilho adamantino, hábito prismático bipiramidal, multifacetados, com arestas retas e uniformes quanto ao tamanho. A média ponderada, determinada a partir de um conjunto de 10 zircões, forneceu uma idade de $2974 \pm 15$ Ma (Fig. 3).

Para a rocha metavulcânica félsica do GT, foi analisado um conjunto de 8 zircões. Esses exibem coloração amarelo-avermelhado, sendo geralmente translúcidos. São cristais automórficos, alongados e com hábito prismático bipiramidal, que juntos forneceram uma idade

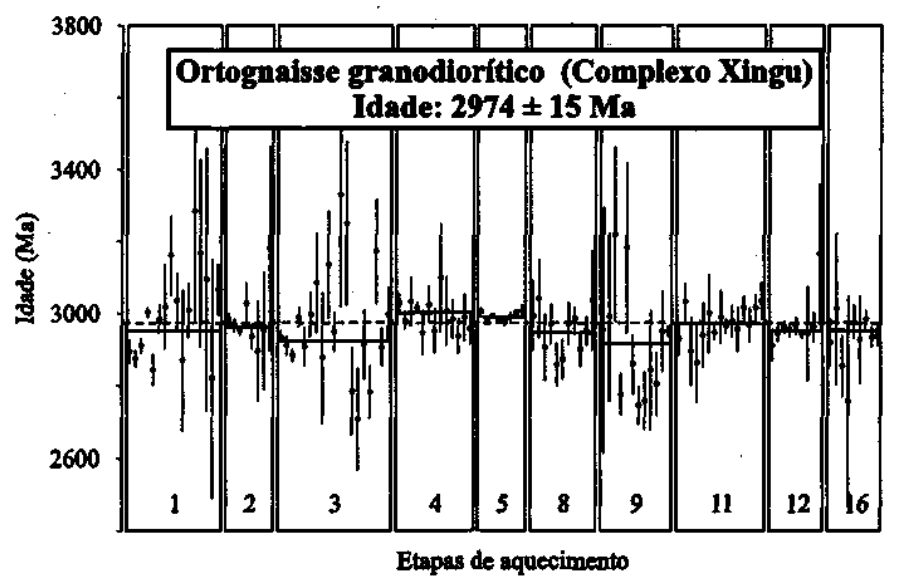

Figura 3-Diagrama de idades ${ }^{207} \mathrm{~Pb}{ }^{206} \mathrm{~Pb}$ dos zircões do ortognaisse granodiorítico do CX.

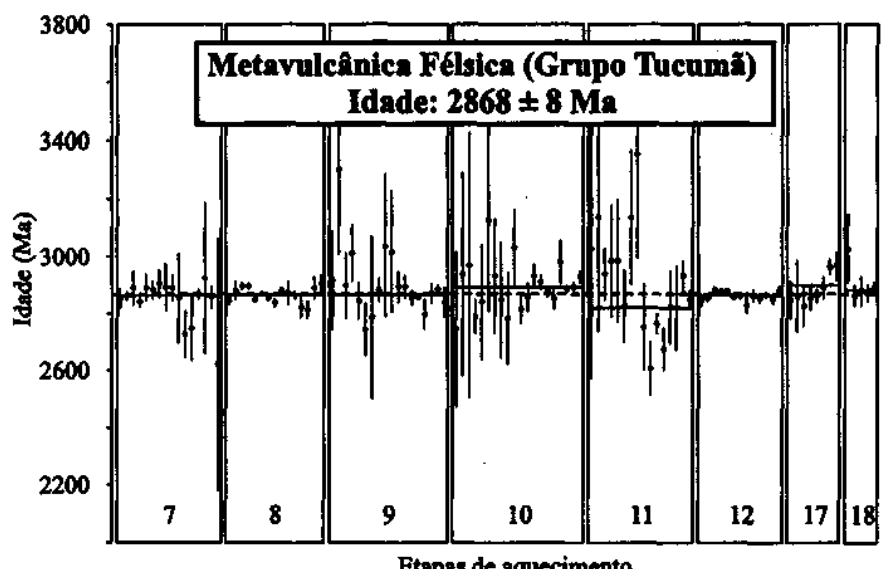

de $2868 \pm 8$ Ma (Fig. 4).

Figura 4 - Diagrama de idades $\quad{ }^{207} \mathrm{~Pb} /{ }^{206} \mathrm{~Pb}$ dos zircões da rocha meta vulcânica féis iça do GT.
Os zircões do metagranodiorito do GRM apresentam uma coloração castanha. São translúcidos a transparentes, com brilho adamantino e superficie áspera, com a presença de pequenas bolhas transparentes ou opacas. Os cristais são automórficos, apresentando por vezes bordas corroídas. Foram analisados 6 zircões que definiram uma idade de $2852 \pm 16 \mathrm{Ma}$ (Fig. 5).

Os zircões do granitóide estratóide do GP são translúcidos e castanho-claros a escuros, com pequenas bolhas transparentes ou opacas. São cristais alongados, automórficos a sub-automórficos, com hábito prismático. Quatro cristais do granito forneceram uma idade de 2736 $\pm 24 \mathrm{Ma}$ (Fig. 6).

$\mathrm{O}$ método de evaporação de $\mathrm{Pb}$ em zircão fornece uma informação parcial através da idade aparente ${ }^{207} \mathrm{~Pb} /{ }^{206} \mathrm{~Pb}$, sem determinação das razões $\mathrm{Pb} / \mathrm{U}$. As idades $\mathrm{Pb} / \mathrm{Pb}$ devem por isso, ser interpretadas como idades mínimas da cristalização dos zircões. Porém, vários estudos comparativos utilizando os métodos $\mathrm{Pb}-\mathrm{Pb}$ e U/Pb em zircões de mesmas amostras foram realizados em rochas magmáticas e mostraram que as idades fornecidas por ambos são similares. Isto justifica o uso do método $\mathrm{Pb} / \mathrm{Pb}$ na determinação da idade de cristalização de rochas, mesmo que estas tenham sofrido os efeitos do metamorfismo e deformação (Kober 1986, 1987, Kober et al 1989, Kröner et al. 1996, 1999). E oportuno ressaltar que em condicões severas de metamorfismo (fácies granulítico), as idades ${ }^{207} \mathrm{~Pb}{ }^{206} \mathrm{~Pb}$ podem apresentar valores comprovadamente abaixo das idades fornecidas pelo método $\mathrm{U} / \mathrm{Pb}$ e calculadas em diagrama Concórdia (Paquette et al. 1994).

A utilização do método de evaporação de $\mathrm{Pb}$ em zircões com filamento simples não modifica os conceitos de interpretação da idade ${ }^{207} \mathrm{~Pb} /{ }^{206} \mathrm{~Pb}$ obtida a partir do método original. No entanto as idades obtidas, via de regra, apresentam desvios mais elevados e dependem tanto da escolha dos zircões analisados, como do tratamento estatístico

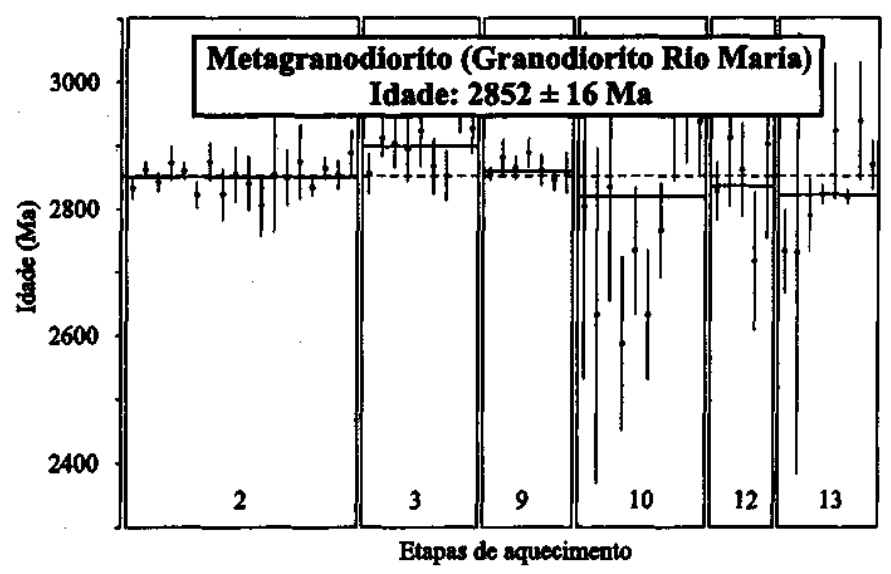

Figura 5 - Diagrama de idades ${ }^{207} \mathrm{~Pb}{ }^{206} \mathrm{~Pb}$ dos zircöes do metagranodiorito do GRM.

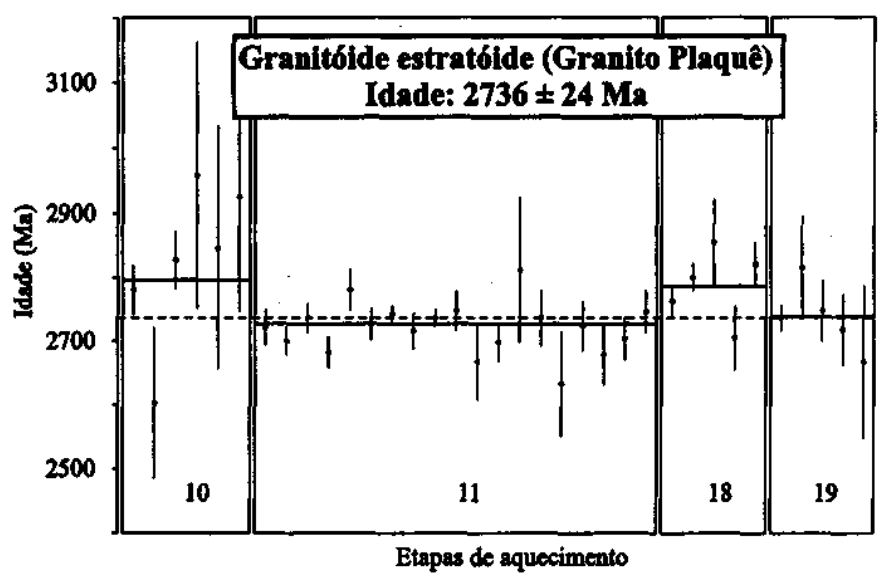

Figura 6-Diagrama de idades ${ }^{207} \mathrm{~Pb} /{ }^{206} \mathrm{~Pb}$ dos zircões do granitóide estratóide do GP. 
dos resultados analíticos (Macambira et al. 1994, Moura et al 1996, Gaudette et al. 1998).

Tendo em vista o número elevado de zircões analisados e a consistência dos resultados isotópicos obtidos para os cristais do ortognaisse granodiorítico do CX, da rocha metavulcânica félsica do GT e do metagranodiorito do GRM, as respectivas idades de $2974 \pm 15 \mathrm{Ma}$, $2868 \pm 8 \mathrm{Ma}$ e $2852 \pm 16 \mathrm{Ma}$, são interpretadas como sendo a da cristalização dessas rochas magmáticas.

No caso do granitóide estratóide do GP apenas 4 cristais, dos mais de 20 analisados, foram aproveitados para o cálculo da idade. $\mathrm{O}$ valor de $2736 \pm 24$ Ma representa a média entre dois grupos de zircões de idades distintas. Um com idade entre 2,73-2,74 Ga (zircões 11 e 19, Fig. 6) e outro entre 2,78-2,79 Ga (zircões 10 e 18, Fig. 6). Os zircões mais antigos poderiam refietir a presença de um componente herdado. No entanto essa possibilidade precisa de maior investigação, uma vez que os dados fornecidos pêlos mesmos são muito imprecisos (erros elevados sobre a idade), definidos por poucos e dispersivos blocos de razões ${ }^{207} \mathrm{~Pb} /{ }^{206} \mathrm{~Pb}$. Na incerteza da existência desse componente herdado, optou-se pela utilização desses zircões, bem como daqueles de idades mais jovens para 0 cálculo da idade final do granitóide estratóide do GP, explicando o desvio maior sobre a mesma (2736 $\pm 24 \mathrm{Ma})$. A média de idades dos zircões mais jovens é de $2727 \pm 12 \mathrm{Ma}$, mostrando que esses zircões tiveram maior peso na determinação da idade final estabelecida pêlos 4 cristais (2736 Ma). Resultados U-Pb (SHRIMP II) inéditos obtidos na Austrália por um dos autores (JML), em zircões da mesma amostra confirmaram a idade ${ }^{207} \mathrm{~Pb} /{ }^{206} \mathrm{~Pb}$ determinada a partir dos 4 cristais, mostrando que esta corresponde realmente àquela de cristalização da rocha. Alem disto, os dados U-Pb (SHRIMP II) evidenciaram a existência de um componente herdado nos zircões dessas rochas.

\section{INTERPRETAÇÃO DOS RESULTADOS E DISCUSSÃO A}

idade ${ }^{207} \mathrm{~Pb} /{ }^{206} \mathrm{~Pb}$ de $2974 \pm 15 \mathrm{Ma}$ do ortognaisse granodiorítico do CX indica a existência de um episódio magmático, gerador do protólito ígneo desse gnaisse, ocorrido nessa época na região de Tucumã. Essas rochas, junto com os granulitos do Complexo Pium (Rodrigues et al 1992, Pidgeon et al. 1998), comprovam o envolvimento de porç̃̃es de crosta siálica com idade de cerca de 3,0 Ga no âmbito do CCI. A idade de 2,97 Ga indica que, pelo menos, parte dos ortognaisses do CX na região de Tucumã, não derivou do retrabalhamento dos granitóides do TGG, ao contrário do que tinha sido anteriormente sugerido (Costa et al. 1993). A comparação com as idades modelo $\mathrm{Sm} / \mathrm{Nd}$, disponíveis para os gnaisses e os granitóides da PMC (Sato \& Tassinari 1997) confirma que o tempo entre a acreção de material mantélico e a formação dessas rochas foi muito curto.

A idade ${ }^{207} \mathrm{~Pb} / 206 \mathrm{~Pb}$ em zircão de $2868 \pm 8 \mathrm{Ma}$ obtida para a rocha vulcânica félsica constitui uma primeira referência cronológica para a formação das sequências de greenstone belts da região de Tucumã. A idade é próxima daquela fornecida pelo metagranodiorito do GRM, indicando tratar-se provavelmente de uma das manifestações do vulcanismo, correspondente ao topo do GT, podendo representar ainda o equivalente vulcânico nos greenstone belts do magmatismo gerador dos granitóides do GRM. Na região de Rio Maria, as rochas vulcânicas félsicas das sequências superiores dos greenstone belts do Grupo Andorinhas (Grupo Lagoa Seca) possuem idades U/Pb em zircão de $2904+297-22$ Ma (Macambira \& Lancelot 1996) e $2979 \pm 5$ Ma (Pimentel \& Machado 1994). Na região da Serra dos Gradaús, complexos máfíco-ultramáficos intrusivos nos greenstones, forneceram uma idade U/Pb de $2970 \pm 7 \mathrm{Ma}$ (Pimentel \& Machado 1994). Os dados evidenciam que um intervalo de tempo prolongado, de mais de 100 Ma, foi necessáriopara a formação dessas sequências.

A idade ${ }^{207} \mathrm{~Pb} /{ }^{266} \mathrm{~Pb}$ em zircão de $2852 \pm 16 \mathrm{Ma}$ do metagranodiorito do GRM indica que o evento plutônico em torno de 2,87 Ga, bem caracterizado nas regiões de Rio Maria e da Serra dos Gradaús (Lafon \& Scheller 1994, Lafon et al. 1995, Macambira \& Lancelot 1996, Pimentel \& Machado 1994) estende-se à região de Tucumã, fornecendo também uma idade mínima para a formação das sequências de greenstone belts.

Esses resultados levantam a questão da existência de um embasamento siálico para as sequências greenstone belts da região de Tucumã. Cerca de 120 Ma separa a formação do ortognaisse granodiorítico do CX $(2,97 \mathrm{Ga})$ das rochas metavulcânicas dos greenstones $(2,85 \mathrm{Ga})$, sugerindo que aquele possa constituir o embasamento dos greenstones do Grupo Tucumã. Porém, não é descartada a possibilidade de existirem rochas metavulcano-sedimentares mais antigas no
GT, como já foi comprovado para as outras sequências de greenstone belts do sul da PMC (Macambira \& Lancelot 1996, Pimentel \& Machado 1994).

$\mathrm{A}$ idade ${ }^{207} \mathrm{~Pb} /{ }^{206} \mathrm{~Pb}$ de $2736 \pm 24 \mathrm{Ma}$ definida para o granitóide do GP demonstra que sua geração é mais nova que aquela dos granitóides do TGG. Por se tratar de um granito com características de magmatismo sin-colisional gerado por fusão crustal e relacionado à evolução do CCI, a idade de $2736 \pm 24 \mathrm{Ma}$ indica a época mais provável da estruturação deste cinturão, enquanto que o TGG comportava-se, como um bloco estável. No período entre 2,76 e 2,75 Ga, na região da Serra dos Carajás, o preenchimento de bacias com as formacões vulcano-sedimentares do Grupo Grão Pará (Wirth et al 1986, Machado et al. 1991, Trendall et al. 1998) indicam condições geodinâmicas diferentes daquelas que propiciaram a formação do granitóide do GP na região de Tucumã. Ainda na Serra dos Carajás, as idades $\mathrm{U} / \mathrm{Pb}$ em zircões e titanitas, de $2573 \pm 2 \mathrm{Ma}$ (Machado et al. 1991) e $\mathrm{Pb} / \mathrm{Pb}$ em zircões de $2560 \pm 37 \mathrm{Ma}$ (Souza 1996), também obtidas em granitóides foliados, poderiam representar um evento termo-tectônico de natureza similar àquele evidenciado na região de Tucumã. A idade de 2,74 Ga do granitóide do GP sugere que o CCI tenha se desenvolvido posteriormente à formação das sequências vulcano-sedimentares da região de Carajás e não anteriormente como foi proposto por Costa et al (1995) e Costa \& Hasui (1997). Por outro lado, esse resultado implica que os processos colisionais já teriam iniciados há 2,74 Ga e não em torno de 2,60 Ga como proposto por Teixeira \& Eggler (1994).

As idades $\mathrm{Rb} / \mathrm{Sr}$ em rocha total de 2,57 Ga, 2,68 Ga e 2,74 Ga, para ortognaisses do CX e granodioritos e monzogranitos do GRM da região de Tucumã, respectivamente obtidas por Lafon et al. (1991), são sensivelmente inferiores às idades determinadas pelo método $\mathrm{Pb} / \mathrm{Pb}$ em zircão das rochas similares. Portanto, elas devem ser interpretadas como resultantes de uma perturbação do sistema isotópico $\mathrm{Rb} / \mathrm{Sr}$ relacionada ao metamorfismo e à deformação que afetaram essas rochas, como foi postulado para as outras regiões da PMC (Macambira \& Lafon 1995).

As características petroquímicas das rochas félsicas do GT e do GRM, na região de Tucumã sugerem um ambiente de arcos de ilhas (Macambira \& Vale 1997). Na região de Rio Maria, as características estruturais e geoquímicas das rochas félsicas dos terrenos granitogreenstones levaram Souza et al. (1997) a propor uma estruturação desses terrenos em contexto de margem ativa e de fechamento de bacias marginais. Com base nesses dados, pode-se interpretar a estruturação da porção sul da PMC através da agregação de arcos de ilhas à sul, com uma massa continental à norte, durante um episódio de colisão gerador de movimentos compressivos. A idade e o tempo de atuação desse evento ainda não estão totalmente definidos. Na região de Rio Maria, Althoff et al (1995) consideraram que a estruturação regional é resultante de um evento de encurtamento, na direção N-S, com duração de pelo menos $100 \mathrm{Ma}$, afetando os terrenos granitogreenstones entre 2,97 e 2,87 Ga. Esse mesmo evento foi evocado por Oliveira et al. (1995) para descrever o arranjo estrutural do Grupo Sapucaia, à norte da região de Rio Maria.

A ausência, até o momento, de registros geocronológicos entre 2,85 e 2,76 Ga em toda a Província Mineral de Carajás sugere que o episódio compressivo não se processou neste período, sendo substituído por uma fase de quiescência tectônica ou pela atuação de uma fase distensiva, que propiciou a formação das sequências meta vulcano-sedimentares da região da Serra dos Carajás, em torno de 2,76 Ga.

A retomada dos movimentos compressivos, que provocou a colisão entre massas continentais, seria responsável pela estruturação do CCI e teria induzido o espessamento e fusão da crosta em profundidade, gerando os granitóides do GP a 2,74 Ga. De acordo com os dados geocronológicos (Machado et al 1991, Souza 1996), essa fase teria perdurado até cerca de $2,5 \mathrm{Ga}$, afetando essencialmente a porção norte da PMC (região da Serra dos Carajás).

Agradecimentos Esse trabalho é uma contribuição ao projeto PADCT/FINEP (conv. FINEP/FADESP 65.92.0025.00). Os autores agradecem ao $\mathrm{CPGG} / \mathrm{CG} / \mathrm{UFPa}$ pelo apoio financeiro e à CPRM/Belém pelo apoio logístico durante os trabalhos de campo. Deferências especiais são dadas aos Professores Thomas Scheller, Moacir Macambira e a todos os pesquisadores que integram a equipe do Pará-Iso. Somos gratos aos relatores anónimos que avaliaram e criticaram este artigo para a publicação. 


\section{REFERÊNCIAS}

Althof, J F, Barbey P, Boullıer R, Dall"Agnol R 1995 Composıção e estrutura dos granıtóldes arqueanos da regłăo de Marajoara Belem, Boletrm do Museu Paraense Emillo Goeldi, 7 5-26

Araújo O J B , Mala R G N, João X S J , Costa J B S 1988 A megaestrutura arqueana da Folha Serra dos Carajăs In SBG, Congresso Latuno-Amencano Geologia, 7 Belém, Anats, p 324-338

Araújo O J B \& Malá R G N 1991 Programa de Levantamentos Geológıcos Básıcos do Brasil Programa Grande Carajás Folha SB-22 Z A Estado do Pará Brasnıa, DNPM/CPRM, 164p (Texto exphicatıvo)

Araújo O J B , Macambıra E M B , Vale A G, Oliverra J R, Sılva Neto C S, Costa E J Santos A , Pena Filho J I de C, Neves A P, Joăo X S J, Costa J B S 1994 Primeir integfaçăo das invesugaçōes geológicas do Programa Grande Carajás na regiào SE do Estado do Pará In SBG, Simpósıo Geologıa Amazônıa, 4, Belém, Anats, p 299-300

Avelar VG. Lafon J M, Scheller T, Araújo OJ B, Macambira EM B 1994 Geocronologıa Pb-Pb por evaperação de zırçăo e Rb/Sr em rocha total do Gramito Seringa, Provineıa Mineral de Carajás ln SBG, Congresso Brasıleıro Geologia, 38. Balneáno Cambonú, Boletim de resumos expandidos, 2387.389

Avelar V G, 1996 Geocronologra Pb-Pb por evaporaçäo em monocrisral de zarcão do magmausmo da regiáo de Tucuma, SE do Estado do Pará, Amazôna Ortental Centro de Geoclêneias, Universıdade Federal do Pará, Belém, Dissertação de Mestrado, 149p

Barbosa A A \& Lafon J M 1996 Geocronologia Pb-Pb e Rb/Sr de granutóldes arqueanos da reguão de Redenção - Sul do Pará Revista Brastlerra de Geociências, 26 255-264

Costa J B S , Araújo O J B , João X S J , Maıa R G N, Macambıra E M B, Vale A G , Santos A. Pena Filho J I C , Neves A P 1994 Panorama tectonoestrutural da regtäo sudeste do Estado do Pará SBG. Simpósto Geologia Amazôna, 4 Belém, Anars. p 314-317

Costa J B S , Araújo O J B , Santos A, Joăo X S J , Macambıra M J B, Lafon J M 1995 A Provincia Mineral de Carajás aspectos tectono-estruturaus, estratugráficos geocronológicos Belém. Boletim do Museu Purclense Emílo Goeldh, 7 199-235

Costa $]$ B S \& Hasuı Y 1992 Aspectos fundamentaus do Proterozóıco Médıo da Amazônıa Brasılerra Revisıa Brasileura de Geociêncras, 22 487-492

Costa J B S \& Hasu Y 1997 Evolução Geológica da Amazönıa Belém, FINEP, SBG, Núcleo Norte, p $15-90$

Costa J B S , Macambura E M B V Vale A G , Pinherro R V L . Joâo X S J 1993 Evoluçāo litoestrutural da regıào de São Félıx do Xingu-Serra dos Carajás Geoctênctas, $12315-332$

Costa J B S, Pinheiro R V L, João X S J , Araújo O J B 1991 Esboço estrutural do Proterozóıco Médio da Amazônıa Onental Belém, Boletrm do Museu Paraense Emilto Goelds 3 9-24

Dall' Agnol R, Lafon J M , Macambira M J B 1994 Proterotolc anorogenc magmatism in the Central Amazonian Province, Amazonan Craton Geochronological, petrological and geochemical aspects Mimeralogy and Petrolog), 50 113-138

Dall'Agnol R, Souza Z S, Althoff F J, Macambira M J B , Lette A A S 1996 Geology and geochemustry of the Archean Rio Marla granite-greenstone terrain, Carajas Province, Amazonian craton In SBG Symposium on Archean terranes of the south ameriçan platform, Brasília, Exiend Abstracts P 29-30

DOCEGEO 1988 Revisão lito-estrangráfica da Provincia Mineral de Carajás Lito-estrangrafia e principas depositos mineras In SBG, Congresso Brasileiro Geologia, 35, Belém, Anexo aOs Anats, p 1 1.54

Duarte K D , Pereira E D , Dall'Agnol R, Lafon J M 1991 Geologia e geccronologia do Granito Mata Surrão-Sudoeste de Rio Marı (Pa) In SBG. Simposio Geologia Amazôna, 3, Belém, Anass, p 7-20

Gastal M CP, Macambira M J B , Medeıros M , Dall'Agnol R 1987 Idades e geoquímuca 1sotópıca Rb/ST do Granto Musa e do Granodionto Rıo Mana, Amazônıa Onental Geoch Brasiliensis, 1247.259

Gaudette H E, Lafon I M, Macambra M J B, Moura C A V, Scheller T [998 Companson of single filament $\mathrm{Pb}$ evaporation/ionzanion zircon ages with conventional U-Pb results Examples from the Precambnan of Brazil Acetto pelo Journal of South American Earth Sctences 11 351-363

Gauderte H E , Lafon J M , Moura C A V , Scheller T 1993 Datação de monozurcāo por evaporação de $\mathrm{Pb}$, no Laboratớrı de Geologıa Isotópıca-UFPa Metodologıa e primeiros resultados In Congresso Brasileiro Geoquímica, 3, Brasílıa, Boletum de resumtos expandidos, $\mathrm{p}$ 236-237

Hırata W K, Rıgon J C, Kadekaru K, Cordeiro A A C, Meireles E M 1982 Geologia regional da Provincıa Mineral de Carajás In SBG. Simpósıo Geologia Amazóna, 1, Belém, Anass, 1 100-110

João X S J \& Araújo J B 1992 Magmausmo granítıco sın-Cisalhamento ltacaúnas no SW do Estado do Pará In SB̈G, Congresso Brasiletro Geologia, 37, Sz̊o Pasto, Resumos expandidos, Săo Paulo, $236-38$

Kober B 1986 Whole-gram evaporation for ${ }^{207} \mathrm{~Pb} /{ }^{206} \mathrm{~Pb}$-age-investigations on single zircons using a double-filament thermal jon source Contribution to Mineralogy and Petrology, 93 482-490

Kober ${ }_{207} 1987$ Single zurcon evaporation combined with $\mathrm{Pb}+$ emitter-bedding for ${ }^{207} \mathrm{~Pb} /{ }^{206} \mathrm{~Pb}$-age investigations using thermal ion mass spectrometry, and implicauons to zirconology Coniribution to Mineralogy and Petrology, 96 63-71

Kober B, Pidgeon R T, Lippolt H J 1989 Single-zircon dating by stepwise Pb-evaporation constrains the Archean history of detrital zicons from the Jack Hills, Western Australia Earth Planetury Science Letters, 91 286-296

Kroner A, Hegner E, Wendt J I, Byerly G R 1996 The oldest part of the Barberton granitoid-greenstone terrain. South Africa evidence for crust formation between 35 and $37 \mathrm{Ga}$ Precambran Research, 78 105-124

Kroner A, Jaequel P, Brandl G, Nemchm A A , Pidgeon R T 1999 Single zircon ages for grantoid gnetsses in the Central Zone of the Limpopo belt, southern Africa and geodynamic significance Precambrian Research 93 299-337
Lafon J M \& Macambira M J B 1990 Datation Rb/Sr de la Granodionte Cumaru, Serra dos Gradaís, PA $C R$ Acad SCi de Parts, 310 1635-1641

Lafon J M, Pereira ED, Macambıra E M B, Vale A G, Barradas J A S 199 Geocronologta Rb/Sr da tegıăo de Săo Felix do Xingu Resultados prelımunares In SBG, Stmpósio Geologia Amazốnia, 3, Belém, Anais, p 21-35

Lafon J M \& Scheller T 1994 Geocronologia Pb.Pb em zircão do granodionto Cumaru Serra dos Gradaús. Pa in SBG, Simpósıo Geologıa Amazônıa, 4, Belém, Boletm de resumos expandulos, $\mathrm{p}$ 321-324

Lafon J M, Rodngues E, Duarte K D 1994 Le Granute Mata Surråo Un magmatısme monzogranıque contemporain des associations tonahtiques-trondhjémitıques granodiontiques archéennes de la région de Rıo Marna (Amazonie Orientale, Brésil) $C R$ Acad Sat de Parts, 318 643-648

Lafon JM, Rodrigues E, Macambira EM B, Pereira ED 1995 Magmausme anorogénıque du Protérozosque inféneur dans la régıon de Sāo Félıx do Xıngu-Tucumã (Amazonie Orientale. Brésil) Nouvelles donnés géochronologiques $C R$ Acad St de Parts, 320937.944

Macambıra E M B , João X S J , Souza E C 1996 Geological and petrochemical aspects of the Plaque grante - southern of the Pará State In SBG Symposium on Archean terranes of the south amencan platform, Brasílja, Extend Abstracts P 73-75

Macambira EMB \& Tassinan CCG 1998 Estudos Sm-Nd no Complexo Máfico-Ultramáfico da Serra da Onça - Sul do Pará Implicaçōes geocronológıcas e geotectônicas In SBG, Congresso Brasleıro Geologia, 40, Belo Horizonte, Anats, p 463

Macambira E M B, \& Vale A G 1996 Aspectos geológıcos e metalogenéncos do "greenstone belt" de Tucumã - Sul do Pará In SBG, Congresso Brasileiro Geologia, 39. Salvador, Anars, 3 230-232

Macambira E M B, \& Vale A G 1997 Programa Levantamentos Geologicos Básicos do Brasıl Programa Grande Carajás Folha SB 22-Y B, Sāo Félıx do Xıngu Estado do Pará Belém, Convêno DNPM/CPRM, 344p (Texto)

Macambira M J B 1992 Chronologie U.Pb, Rb/Sr, K-Ar et croussance de la crouise continental dans l'Amazonie du sud-est, exemple de la régson de Rio Mario Province de Carajás, Brésıl Universıdade de Montpellher ll, Montpellier, Tese de Doutoramento, $212 \mathrm{p}$

Macambira M J B \& Dall'Agnol R 1997 Zircon age for the Paleoproterozolc Jamon granite, SE Carajás province, Brazll new evidence of rocks older than $31 \mathrm{Ga}$ in the Amazonian craton In South Atnerican Symposium on isotope Geology, 1, Campos. do. Jordao, Extended Absracs, p 186187

Macambıra M I B , Lafon J M , Barradas J A S 1991 LeGrante de Xınguara, témoun d un magmatısme monzogranituque dans l'Archéen de l'Amazonte orıentale. Brésıl $C$ $R$ Acad Sct de Pats. 313781.785

Macambıra M J B \& Lafon J M 1995 Geocronologia da Provincıa Mıneral de Carajás, sintese dos dados e novos desafios Belém, Boletım Museu Paraense Emilho Goeldt, $7263-288$

Macarnbıra M J B \& Lancelot J 1991 Hisıóna arqueana da regıăo de Rıo Marıa, SE do Estado do Pará, registrada em zurcóes detríticos de greenstone belt e de cobertura plataformal In SBG, Simpósıo Geologıa Amazôna, 4, Belém, Anass, p 59.69

Macambira M J B \& Lancelot J 1996 Time constraints for the formation of the Archean Rio Maria crust, southeastern Amazonian Ctaton, Brazil Internatonal Geology Review, $381134-1142$

Macambra M J B , Moura C A V Lafon J M , Scheller T Gaudete H E 1994 O método $\mathrm{Pb}$ - $\mathrm{Pb}$ por evaporaçzo em zırç̌̃o avaliaçāo dos dados obtudos no Laboratórı de Geologia lsotopica da UFPa In SBG, Congresso Brasıleıro Geologıa, 38, Balneárıo Cambonú, Boletum de resimos expandidos, 2 404-405

Macambıra M I B , Pereıra E D . Kawashıta K , Mederros H 1988 Contnbuçăo a hıstóna tectono-termal da regtão da Serra das Andornnhas (SE do Pará) com base em dados geocronológicos In SBG. Congresso Brasıleıro Geologia, 35. Belém, Boletum de resumos expandkdos, 3 1468-1477

Macambira M J B \& Scheller T 1994 Estudo comparatıvo entre métodos geocronológicos aplicados em zircōes, o caso do Granodionto Rio Maria In SBG, Simpósıo Geologıa Amazônıa, 4, Belém, Boletrm de resumos expandrass, p 343-346

Macambira M J B . Pidgeon R T , Lafon J M 1998 Ctescimento crustal arqueano regıstrado em zurcơes de sedımentos da regıăo de Rio Mana, Províncıa Carajás Pará In SBG, Congresso Brasilero Geologia, 40, Belo Horizonte Anas p 55

Machado N, Lundenmayer Z, Krogh T E , Lundenmayer D 1991 U-Pb geochronology of Archean magmatism and basement in the Carajás area, Amazon Shueld, Brazil Precambrian Research 49 329-354

Montalvão R M G. Tassınan C C G. Teıxęra W, Vasconn A 1988 Caracıerızaçă geocronológıca $\mathrm{Rb} / \mathrm{Sr}$ dos terrenos granodıoríticos e trondhjemítıcos da reguāo de Rıo Marna, sul da Serra dos carajás In SBG, Congresso Brasılęro Geologia, 35. Belém. Anaus, 3 1478-1487

Moura C A V , Gaudette H E, Macambira M J B , Lafon J M , Scheller T 1996 Dalaçăo de monocrıstaıs de zırcāo por evaporaçāo de $\mathrm{Pb}$ em filamento sımples Comparaçāo com resultados U-Pb In SBG, Congresso Brasilero Geologia, 39, Salvador, Anals, $6.480-483$

Olıvera C G. Santos R V , Leonardos O H 1995 Geologıa e mineralızaçăo aurffera do greenstone belt Sapucaua, Sudeste do Para Belem, Boletm Museu paraense Emílo Goeldr, $761-91$

Olszewsky W J , Gaudette H E, Cheatham M M $1990{ }^{207} \mathrm{~Pb} /{ }^{206} \mathrm{~Pb}$ ages from the Chan Lakes Massuf, NW Maine using single grain direct thermal ionizaton Annual Meeting NE Section Geol Soc of America, Syracuse, 27, $\mathrm{p} 6.1$

Paquette J-L, Nedelec A, Moine B, Rakotondrazafy M 1994 U.Pb, single zircon $\mathrm{Pb}$-evaporation, and Sm-Nd ssotopic study of a granulute domain in SEMadagascar Journal of Geolog, 102523.538

Pıdgeon R T , Macambıra M J B , Lafon J M 1998 Dataçao U-Pb de estruturas primánas e secundárias de zurcōes de granulitos do Complexo Pum, Província de Carajás. Pará in SBG, Congresso Brasileiro Geologia, 40, Belo Horızonte Anars p 56 
Pimentel M.M. \& Machado N. 1994. Geocronologia U-Pb dos terrenos granito greenstone de Rio Maria, Pará. In: SBG, Congresso Brasileiro Geologia, 38, Balneário de Camboriú, Anais, 2:390-393.

Rodrigues E.S.; Lafon J.M., Scheller T. 1992. Geocronologia Pb-Pb da Província Mineral de Carajás: Primeiros resultados. In: SBG, Congresso Brasileiro Geologia, 37, São Paulo, Boletim de resumos expandidos, 2:183-184.

Sato K. \& Tassinari C.C.G. 1997. Principais eventos de acreção continental no Cráton Amazônico baseado em idades-modelo Sm-Nd, calculada em evoluções de estágio único e estágio duplo. In: SBG, Contribuições a Geologia da Amazônia, Belém, FINEP/Núcleo Norte, p.91-142.

Souza S.R.B. 1996. Estudo geocronológico e de geoquímica isotópica da área Pojuca (Província Mineral de Carajás - PA). Centro de Geociências, Universidade Federal do Pará, Belém, Dissertação Mestrado, 106p.

Souza Z.S., Dali' Agnol R., Althoff F.J., Leite A.A.S., Barros C.E.M. 1996. Carajás mineral province: Geological, geochronological and tectonic contrasts on the Archean evolution of the Rio Maria granite-greenstone terrain and the Carajás block. In: SBG. Symposium on Archean terranes of the south american platform, Brasília, ExtendAbstracts.P3|-32.
Souza Z.S., Dall'Agnol. R., Oliveira C.G., Huhn S.R.B. 1997. Geochemistry and petrogenesis of metavolcanic rocks from archaean greenstone belts: Rio Maria region (southeast Pará, Brazil).

Teixeira J.B.G.. \& Eggler D.H. 1994. Petrology, geochemistry and tectonic setting of Archean basaltic and dioritic rocks from the N4 Iron deposit, Serra dos Carajás, Pará. Brazil. Acta Geológica Leopoldinense. (Estudos Tecnológicos). 40:71-114.

Trendall A.F., Basei M.A.S., De Laeter J.R., Nelson D.R. 1998. SHRIMP zircon U-Pb constraints on the age of the Carajás formation Grão Pará group, Amazon craton. Journal of South American Earth Sciences. 11:265-277.

Wirth K.R., Gibbs A.K., Olszewski W.J. 1986. U-Pb ages of zircons from the Grão-Pará group and Serra dos Carajás grani te, Pará, Brazil. Revista Brasileira de Geociências, 16:195-200.

Manuscrito A-971

Recebido em 13 de abril de 1998

Revisão dos autores em 10 de setembro de 1999 Revisão aceita em 15 de setembro de 1999 